\title{
BMJ Open Work-related allergies to storage mites in Parma (Italy) ham workers
}

\author{
Federica Tafuro, Erminia Ridolo, Matteo Goldoni, Marcello Montagni, \\ Antonio Mutti, Massimo Corradi
}

To cite: Tafuro F, Ridolo E, Goldoni M, et al. Workrelated allergies to storage mites in Parma (Italy) ham workers. BMJ Open 2015;5: e007502. doi:10.1136/ bmjopen-2014-007502

- Prepublication history for this paper is available online. To view these files please visit the journal online (http://dx.doi.org/10.1136/ bmjopen-2014-007502).

Received 22 December 2014 Revised 19 March 2015 Accepted 25 March 2015

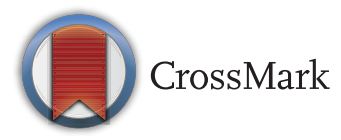

Department of Clinical and Experimental Medicine, University of Parma, Parma, Italy

Correspondence to Professor Massimo Corradi; massimo.corradi@unipr.it

\section{ABSTRACT}

Objectives: To investigate the role of storage mites in the development of allergic diseases among ham production workers, and to search for early alterations in lung function tests and early inflammation markers in exhaled air. Respiratory allergies due to storage mites have been reported in people with various occupations but, although such mites are unavoidable when curing ham, there are no published data concerning ham production workers.

Setting: Secondary care.

Design: Experimental cross-sectional study.

Participants: 220 participants (110 ham production workers and 110 controls) were recruited.

Primary and secondary outcome measures:

Workers answered a medical questionnaire, and underwent spirometry and fraction of exhaled nitric oxide at $50 \mathrm{~mL} / \mathrm{s}\left(\mathrm{FeNO}_{50}\right)$ measurements. Those with allergic symptoms also underwent skin prick tests to determine their sensitisation to airborne allergens. A methacholine test was performed in symptomatic participants when spirometry was normal to assess airways hyper-responsiveness.

Results: Symptomatic storage mite sensitisation was observed in 16 workers (14.5\%) (rhinoconjunctivitis in $15(63 \%)$ and asthma in (4\%)) and 2 controls $(1.8 \% ; p=0.001)$. Higher FeNO 50 values in exposed symptomatic workers compared with healthy control participants $(34.65 \pm 7.49$ vs $13.29 \pm 4.29$ ppb; $p<0.001)$ suggested bronchial and nasal involvement, although their lung function parameters were normal. Regardless of exposure, a FeNO 50 value of $22.5 \mathrm{ppb}$ seems to be $100 \%$ sensitive and $99.4 \%$ specific in distinguishing allergic and non-allergic participants. Multivariate analysis of $\mathrm{FeNO}_{50}$ values in the symptomatic participants showed that they were positively influenced by IgE-mediated allergy $(p=0.001)$ and reported symptom severity $(p=0.041)$, and negatively by smoking status ( $p=0.049)$.

Conclusions: Ham processing workers, as well as workers involved in any meat processing work that includes curing, should be informed about the occupational risk of sensitisation to mites.

\section{INTRODUCTION}

There are more than 60000 mite species throughout the world, some of which are well-

\section{Strengths and limitations of this study}

The main aim of this study was to investigate the role of storage mite (SM) sensitisation in ham production workers, and to quantify the prevalence of allergic disorders in exposed and nonexposed participants.

- Our data demonstrated that fraction of exhaled nitric oxide (FeNO) could be used in conjunction with lung function testing in order to identify workers at risk of airway inflammation who undergo skin prick and methacholine testing.

- The main strength of this study is that our findings provide strong evidence that SMs play a role in the onset of allergic respiratory disorders in ham production workers.

- The main limitation of this study is that environmental monitoring of SM species was not performed, although Astigmata mites (especially Tyrophagus putrescentiae and Lepidoglyphus destructor) are expected, as per the literature.

- One limitation is the small number of skin prick tested participants, but statistical results demonstrated a significant higher prevalence in SM sensitisation in exposed versus non-exposed workers.

known sources of allergens that can sensitise humans and induce allergic reactions. ${ }^{1}$ Mites can be divided into two broad categories on the basis of their abundance and allergenic relevance: $^{1-3}$ pyroglyphids or house dust mites (HDMs), including Dermatophagoides farinae and D. pteronyssinus, the most frequent allergy-causing mites, and the most important and best documented sources of perennial indoor allergens, ${ }^{45}$ and non-pyroglyphids, or storage mites (SMs).

SMs (eg Tyrophagus putrescentiae, Acarus siro and Lepidoglyphus destructor) are extensively found in stored food products, and are responsible for the development of occupational respiratory allergic diseases such as rhinitis and asthma, ${ }^{6} 7$ which have been reported in farmers, ${ }^{8-10}$ grain workers, ${ }^{11} 12$ bakers, ${ }^{13}$ other food workers ${ }^{14}$ and people working with laboratory animals. ${ }^{15}$ It has also been reported that symptomatic employees 
working in a moisture-damaged building had a high prevalence of positive skin prick tests for SMs,${ }^{16}$ although sensitisation to SMs can be found in urban populations having no relation to specific occupations. ${ }^{17} 18$ The prevalence of SMs is largely determined by ambient relative humidity, and sensitisation is greatest in environmental conditions of high relative humidity and temperatures near $25^{\circ} \mathrm{C} .{ }^{19}{ }^{20}$ Furthermore, the mites feed on proteinrich substances of animal or vegetable origin, which explains why some categories of workers are at higher risk of sensitisation.

Published data suggest that sensitisation to SM develops more frequently in patients who are already sensitised to allergens of HDM. ${ }^{17}{ }^{18}$ Sensitisation to SMs in the absence of sensitisation to Dermatophagoides spp has been proposed as a rare event. ${ }^{21}$ Part of sensitisation to SM is thought to be cross-reactivity with certain allergens of HDM, ${ }^{22} 23$ although contradictory results have also been reported. ${ }^{19} 2425$ However, Morales et $a l^{26}$ recently stated that sensitisation patterns to SMs in patients sensitised to HDMs and SMs differ depending on the exposure to SMs.

The Italian province of Parma is well known throughout the world for its hams, which are produced from the haunches of pigs by means of a long process that includes phases of salting, resting, washing and drying, and greasing and curing. By law, Parma ham is cured by hanging the prepared haunches on racks for at least 1 year (and, in some cases, 3 years) after the date of first salting, in darkened, air-controlled cellars at a temperature of $15-23^{\circ} \mathrm{C}$. These conditions favour the formation of a soft surface patina of white mould and mites, which are indispensable for the development of the typical aroma. The arthropods that settle on the surface of a ham include T. putrescentiae (also known as ham mites), which are also found in dairies, grain silos, cultivated mushrooms and grocery stores, and A. siro and L. destructor, thus inevitably leading to the exposure of the workers involved.

However, there are no published data concerning occupational sensitisation to these allergens in a ham production factory. The aim of this study was to fill this gap by determining the frequency of sensitisation to SMs and the role of the mites in the development of allergic respiratory occupational diseases. We also investigated the risk factors, early alterations in lung function testing and early markers of inflammation in exhaled air.

\section{METHODS}

This cross-sectional, case-control study of 220 male workers with a mean age of $39.8 \pm 10.4$ years (110 occupationally exposed employees of 11 ham companies in Langhirano, Parma, and 110 occupationally unexposed employees of 3 light engineering companies in Parma) was conducted between July and November. The groups were matched in terms of age and socioeconomic level, and all of the participants gave their written informed consent to participate in the study.
All of the enrolled participants were administered a screening questionnaire by a physician in order to collect demographic data, and information concerning: their smoking habits; their personal and family histories of allergic diseases such as allergic rhinitis, asthma and atopic eczema; the onset of allergic symptoms; the presence of any symptoms of rhinitis and/or asthma at work or home; and the severity of the symptoms as assessed using a $10 \mathrm{~cm}$ visual analogue scale (VAS). ${ }^{27}$ Atopic status was defined on the basis of a reported skin prick test in the medical history. For those few cases in whom this information was uncertain or not available, we defined atopic status on the basis of medical history, which was collected by an expert specialist.

All of the participants underwent lung function tests at work using a portable spirometer (KOKO Spirometer, Sensor Medics, Yorba Linda, California, USA) in accordance with the current guidelines ${ }^{28} 29$ and multiethnic reference values (global lung initiative (GLI) 2012): $:^{30}$ the best of eight recordings of forced vital capacity (FVC), forced expiratory volume in $1 \mathrm{~s}\left(\mathrm{FEV}_{1}\right)$, the $\mathrm{FEV}_{1} / \mathrm{FVC}$ ratio and forced expiratory flow at $25-75 \%$ of vital capacity $\left(\mathrm{FEF}_{25-75 \%}\right)$ were chosen.

In those participants who referred asthma-like symptoms accompanied by normal spirometry, the non-specific bronchial hyper-reactivity (NSBH) test was performed according to European Respiratory Society (ERS) $^{31}$ and American Thoracic Society (ATS) ${ }^{32}$ guidelines. The results are expressed as the provocative dose of methacholine to cause a $20 \%$ fall in $\mathrm{FEV}_{1}$ (PD20). The combination of methacholine test with a specific skin prick testing (SPT) or specific $\operatorname{IgE}$ may be an appropriate alternative in diagnosing occupational asthma because a specific bronchial challenge was not available in our centre. ${ }^{33}$

The bronchial fraction of exhaled nitric oxide (FeNO) was measured in all of the participants in accordance with the ATS/ERS recommendations, ${ }^{34}$ outside the pollen season, and at approximately the same time of day. The measurements were made using a Hypair Medisoft FeNO group instrument with the participant in a sitting position: an inhalation of ambient air was followed by a constant flow exhalation into a mouthpiece at a flow rate of $50 \mathrm{~mL} / \mathrm{s}\left(\mathrm{FeNO}_{50}\right)$ for at least $10 \mathrm{~s}$. None of the participants were taking anti-inflammatory drugs, and none had a respiratory tract infection in the previous month.

Symptomatic volunteers in the exposed and control groups underwent SPT using standardised, commercially available allergenic extracts (Alk-Abelló A/S, Hørsholm, Denmark) of common aeroallergens and SMs, including tree, grass, weed and ragweed pollens, cat and dog epithelia, dust mites (D. farinae and D. pteronyssinus), mould spores (Alternaria, Cladosporium and Aspergillus fumigatus), latex, and L. destructor, T. putrescentiae and A. siro (SMs). All of the SPTs were carried out on the volar side of the forearm using disposable prick lancets (Stallergenes, Anthony, France). SPTs with histamine $10 \mathrm{mg} / \mathrm{mL}$ and saline, respectively, were used as positive and negative 
controls. The readings were made after $15 \mathrm{~min}$, and wheals with a mean diameter of $>3 \mathrm{~mm}$ were considered positive. $^{35}$

\section{Sample size calculation and statistics}

There are no epidemiological data concerning SM sensitisation in the general Italian population but, on the basis of US data, its prevalence may be $2-3 \% .^{36}$ On the other hand, the expected prevalence in occupationally exposed workers varies widely from $5 \%$ to $33 \%$, depending on the workers' category and the study. We therefore calculated sample size assuming a control prevalence of $2-3 \%$ and a case prevalence of $10-15 \%$. With $\alpha=0.05$ and $\beta=0.20$, exact statistical power analysis indicated that the expected number per group was between 77 and 162, a range that includes the number of workers employed in the ham factories (110). With two groups of 110 participants, the expected minimally significant prevalence for exposed workers was between $12.7 \%$ (baseline 2\%) and 14.5\% (baseline 3\%).

The participants were all male, and their age and lung function and $\mathrm{FeNO}$ values were normally distributed in the two groups. The continuous variables are expressed as mean values \pm SDs, and the nominal variables as frequencies. The normally distributed parameters were correlated using Pearson correlations, and their mean values were compared using a student $\mathrm{t}$ test for independent samples. Multiple comparisons were made using analysis of variance. ORs were calculated using contingency tables and Fisher's exact test because of the sample size. All of the statistical analyses were made using SPSS V.20 software, SPAW charts and Graphpad Prism.

\section{RESULTS}

Table 1 shows the baseline characteristics, lung function parameters and $\mathrm{FeNO}_{50}$ values of the participants of the two groups.

\section{Questionnaire}

Nasal symptoms (sneezing, rhinorrhoea, itchy nose, nasal congestion, itchy eyes, watery eyes) were reported by $31 \%$ of the exposed participants (34/110) and $40 \%$ of the controls $(44 / 110)$, and asthma-like symptoms (coughing, wheezing, shortness of breath) by, respectively, 5\% (5/110) and 3\% (3/110). The most frequent VAS score for the severity of sneezing and rhinorrhoea was 3-4-5/10 in both groups.

\section{Pulmonary function}

The results are shown in table 1: airway obstruction (defined as $\mathrm{FEV}_{1} / \mathrm{FVC} \leq \mathrm{LLN}$ (lower limit of normal) and $\mathrm{FEV}_{1}<\mathrm{LLN}$ ) was evident in three participants: two exposed and one control. Borderline airway obstruction (defined as $\mathrm{FEV}_{1} / \mathrm{FVC}<\mathrm{LLN}$ and $\mathrm{FEV}_{1}>\mathrm{LLN}$ ) was present in eight exposed and seven controls. In those workers with borderline airway obstruction, a methacholine challenge test showed hyper-reactivity in two exposed and one control.

\section{Skin prick tests}

Twenty-eight of the 34 symptomatic exposed participants (82\%) and 24 of the 44 symptomatic controls (55\%) agreed to undergo SPTs, which were positive for at least one allergen in, respectively, $24(86 \%)$ and 19 cases (68\%; table 2).

There was a $14.5 \%$ prevalence of symptomatic sensitisation to SMs in the exposed group (16/110) and a $1.8 \%$ prevalence in the controls $(2 / 110)$. The difference is statistically significant (Fisher's exact test $\mathrm{p}=0.001$ ), with an OR of 9.191 (CI 2.060 to 41.019).

\section{Diagnosed allergies and the responsible allergens}

On the basis of their workplace symptoms and the SPT results, 15 of the ham processing workers were diagnosed as having work-related rhinitis due to SM. ${ }^{37}$ Work exacerbated asthma was diagnosed in one ham processing worker on the basis of his workplace symptoms, SPT results and methacholine test. ${ }^{38}$ There were no diagnoses of occupational rhinitis or asthma in the control group (table 3).

\section{Risk factors}

There was a similar proportion of participants with a previous history of rhinitis, asthma and atopy among the SM-sensitised (4 atopic vs 12 non-atopic before the onset of working activity) and non-sensitised ham production workers (2 atopic vs 6 non-atopic before the onset of

Table 1 Characteristics of the study population

\begin{tabular}{|c|c|c|}
\hline & Exposed participants & Controls \\
\hline Age, years (mean $\pm S D$ ) & $40.3 \pm 10.5$ & $39.3 \pm 10.2$ \\
\hline Caucasians/non-Caucasians & $84 / 26(76 \% / 24 \%)$ & $105 / 5(95 \% / 5 \%)$ \\
\hline Current/former/never-smokers & $45 / 11 / 54$ (41\%/10\%/49\%) & $41 / 25 / 44$ (37\%/23\%/40\%) \\
\hline $\mathrm{FEV}_{1} \%$ pred $($ mean $\pm \mathrm{SD})$ & $96 \pm 12$ & $95 \pm 11$ \\
\hline FVC \% pred (mean $\pm S D)$ & $98 \pm 13$ & $97 \pm 12$ \\
\hline $\mathrm{FEV}_{1} / \mathrm{FVC}($ mean $\pm \mathrm{SD})$ & $78 \pm 6$ & $79 \pm 6$ \\
\hline $\mathrm{FEF}_{25-75} \%$ pred $($ mean $\pm \mathrm{SD})$ & $91 \pm 25$ & $91 \pm 22$ \\
\hline $\mathrm{FeNO}_{50}, \mathrm{ppb}($ mean $\pm \mathrm{SD})$ & $18.6 \pm 10.9$ & $16.4 \pm 8.7$ \\
\hline
\end{tabular}


Table 2 Sensitisation to storage mites (SMs), house dust mites (HDMs), animal dander, pollen and mould in the exposed and control groups

\begin{tabular}{llllll}
\hline & SMs, $\mathbf{n}(\%)$ & HDMs, $\mathbf{n}(\%)$ & Animal dander, $\mathbf{n}(\%)$ & Pollen, $\mathbf{n}(\%)$ & Mould, $\mathbf{n}(\%)$ \\
\hline Exposed $(\mathbf{n}=24)$ & $16(67)$ & $17(71)$ & $5(21)$ & $20(83)$ & $3(13)$ \\
Controls $(\mathrm{n}=19)$ & $2(11)$ & $16(84)$ & $3(16)$ & $14(74)$ & $4(21)$ \\
\hline
\end{tabular}

working activity). The median latency of symptoms from the time of the beginning of exposure was $5.4 \pm 4.5$ years, but there was a statistically significant difference between those who were atopic or non-atopic before starting work $(1.5 \pm 0.6$ years vs $6.8 \pm 4.4$ years; student t test for independent samples: $\mathrm{p}=0.037$ ).

Those sensitised to SM in exposed and control groups were also sensitised to HDM $(\mathrm{n}=18)$. There were 15 workers sensitised to HDM who did not have co-sensitisation to SM, and in this group, 14 were not exposed, with an increased risk of 112 (95\% CI of 9.14 to 1371.80 , Fisher's exact test $\mathrm{p}=0.0002$; table 4 ).

\section{$\mathrm{FeNO}_{50}$}

$\mathrm{FeNO}_{50}$ values were normally distributed in the two groups (Kolmogorov-Smirnov $\mathrm{p}=0.537$ ), and did not correlate with age, anthropometric parameters or the results of the lung function tests.

There was no substantial difference in the values observed in the exposed and control groups, but those of the symptomatic sensitised participants were higher than those of the healthy participants $(34.65 \pm 7.49$ vs $13.29 \pm 4.29 \mathrm{ppb} ; \mathrm{p}<0.001)$. A cut-off value distinguished the allergic and non-allergic participants in the exposed group and the control, with a sensitivity and specificity that were both close to $100 \%$, and, in the population as a whole (ie, regardless of exposure), a value of $22.5 \mathrm{ppb}$ was $100 \%$ sensitive and $99.4 \%$ specific (figure 1 ).

Among the non-allergic participants, there was a statistically significant difference in $\mathrm{FeNO}_{50}$ values between current smokers and non-smokers $(12.4 \pm 4.1$ vs 14.5 $\pm 4.2 \mathrm{ppb}$ ); the ex-smokers had intermediate values (13.5 $\pm 4.4 \mathrm{ppb}$ ). Among the allergic participants, the difference between the current smokers and non-smokers was close to significant $(p=0.06)$; although values in the ex-smokers cannot be compared because of the small size of the subgroup (only 3 participants), they were similar to those of the smokers (figure 2).
$\mathrm{FeNO}_{50}$ levels and the VAS symptom severity scores of the allergic participants were related, although not significantly so $(r=0.29 ; p=0.06)$, but there was a significant correlation between the participants with negative SPT results, albeit with a lower $r$ value $(r=0.17 ; \mathrm{p}=0.026)$.

Multivariate analysis of the symptomatic participants' $\mathrm{FeNO}_{50}$ values showed that they were positively influenced by the presence of IgE-mediated allergy $(\mathrm{p}=0.001)$ and symptom severity $(\mathrm{p}=0.041)$, and negatively by smoking status $(\mathrm{p}=0.049$; table 5$)$.

\section{DISCUSSION}

To the best of our knowledge, this is the first study designed to investigate the role of SM sensitisation in ham production workers, and the first study to quantify the prevalence of allergic disorders due to such sensitisation in exposed and non-exposed participants in northern Italy. Our data demonstrate that FeNO, which is a recognised biomarker of airway eosinophilic inflammation, could be used in conjunction with lung function testing in order to identify workers at risk of airway inflammation who should undergo skin prick and methacholine testing.

Our survey of a population of 220 working men revealed a high prevalence of reported allergic symptoms $(78 / 220,35 \%)$, which is in line with the findings of a large-scale study of western Europeans $(40 \%),{ }^{39}$ and observations that atopic diseases, and work-related rhinitis and asthma, are increasing worldwide for reasons that have not yet been fully explained. ${ }^{40}$ The most frequently reported symptoms were rhinorrhoea, nasal itching, sneezing, photophobia, lacrimation and ocular pruritus; whereas cough, dyspnoea and wheezing were less frequent. Our finding that rhinitis-like symptoms were nearly 10 times more prevalent than asthma-like symptoms (78 vs 8 ) are in line with previous observations, ${ }^{41}$ although some non-allergic conditions such as

Table 3 Work-related and allergic symptoms and SPT results

\begin{tabular}{lll} 
& Exposed participants, n (\%) & Controls, n (\%) \\
\hline Referral allergic symptoms & $34 / 110(31)$ & $44 / 110(40)$ \\
Workers who underwent SPT & $28 / 110(25)$ & $24 / 110(22)$ \\
Sensitised workers on SPT & $24 / 28(86)$ & $19 / 24(68)$ \\
Work-related rhinitis (SPT+ to SMs) & $15(63)$ & - \\
Allergic rhinitis (perennial and intermittent) & $7(29)$ & 18 \\
Work-related asthma (SPT+ to SMs and pollen) & $1(4)$ & - \\
Allergic asthma & $1(4)$ & 1 \\
SMs, storage mites; SPT, skin prick testing. & &
\end{tabular}


Table 4 Sensitisation profile to HDMs and SMs, in exposed and controls

\begin{tabular}{|c|c|c|c|c|c|c|}
\hline \multirow[b]{2}{*}{ Patient } & & \multicolumn{2}{|l|}{ Sensitisation HDMs } & \multicolumn{3}{|c|}{ Sensitisation SMs } \\
\hline & & $\begin{array}{l}\text { Dermatophagoides } \\
\text { pteronyssinus }\end{array}$ & $\begin{array}{l}\text { Dermatophagoides } \\
\text { farinae }\end{array}$ & $\begin{array}{l}\text { Lepidoglyphus } \\
\text { destructor }\end{array}$ & Acarus sirus & $\begin{array}{l}\text { Tyrophagus } \\
\text { putrescentiae }\end{array}$ \\
\hline \multirow[t]{17}{*}{ Exposed } & N1 & + & + & & + & + \\
\hline & N2 & & + & + & + & + \\
\hline & N3 & + & + & + & + & + \\
\hline & N4 & + & + & + & + & + \\
\hline & N5 & + & + & + & + & + \\
\hline & N6 & + & + & + & & + \\
\hline & N7 & + & + & + & + & + \\
\hline & N8 & + & + & + & & + \\
\hline & N9 & + & + & & & + \\
\hline & N10 & + & + & + & + & + \\
\hline & N11 & + & & & + & + \\
\hline & N12 & + & + & + & + & + \\
\hline & $\mathrm{N} 13$ & & + & + & + & + \\
\hline & N14 & + & + & + & + & + \\
\hline & N15 & + & + & + & + & + \\
\hline & N16 & + & & + & + & + \\
\hline & N17 & + & + & & & \\
\hline \multirow[t]{16}{*}{ Controls } & N1 & + & + & & + & + \\
\hline & N2 & + & + & + & & + \\
\hline & N3 & + & + & & & \\
\hline & N4 & + & + & & & \\
\hline & N5 & + & + & & & \\
\hline & N6 & + & + & & & \\
\hline & N7 & & + & & & \\
\hline & N8 & + & + & & & \\
\hline & N9 & + & + & & & \\
\hline & N10 & + & + & & & \\
\hline & N11 & + & & & & \\
\hline & N12 & + & + & & & \\
\hline & N13 & & + & & & \\
\hline & N14 & + & + & & & \\
\hline & N15 & + & + & & & \\
\hline & N16 & + & + & & & \\
\hline
\end{tabular}

infections, hormonal imbalance and exposure to physical agents, can cause similar ocular and nasal symptoms, and alter the reported data. ${ }^{42}$ Moreover, we observed that the prevalence of nasal-related symptoms in the exposed participants was less than in the controls; we speculate that the healthy worker effect could be a possible explanation, since controls were not exposed to airway pollutants.

Our hypothesis that ham production worker are exposed to the SMs that develop during curing in cellars can possibly be extended to workers involved in any meat processing work that includes curing. The SPT results showed that the prevalence of respiratory allergic disorders in those exposed and sensitised to SM was $14.5 \%$, in line with findings in bakers, farmers and researchers handling laboratory animals, ${ }^{8-15}$ and $1.8 \%$ in the controls $(\mathrm{OR}=9.2)$, which is similar to the 2.3$3.3 \%$ prevalence of serum $\mathrm{IgE}$ sensitisation to $A$. siro and L. destructor found in a south-western Ohio populationbased survey. ${ }^{36}$
Furthermore, 15 of the exposed allergic workers were diagnosed as having work-related rhinitis (symptoms at work that improved during weekends and holidays, and a positive SM to SPT), and a diagnosis of work-related asthma was confirmed in 1 (symptoms at work that improved during weekends and holidays, peak expiratory flow (PEF) monitoring and a positive SM to SPT). Although the diagnoses were not confirmed by specific challenges, the prevalence of work-related rhinitis and asthma was, respectively, $13.6 \%$ (15/110) and $0.9 \%$ (1/110); however, these findings cannot be compared with those of other studies because prevalence data depend on the methods used for diagnosis (questionnaires, objective evaluations), ${ }^{43}$ and there are no other studies of ham production workers.

We analysed various factors in order to highlight possible causes of the risk of developing sensitisation to mites in occupational settings, including production characteristics (the type of production, quantities produced, duration of curing), prevalent tasks, and 


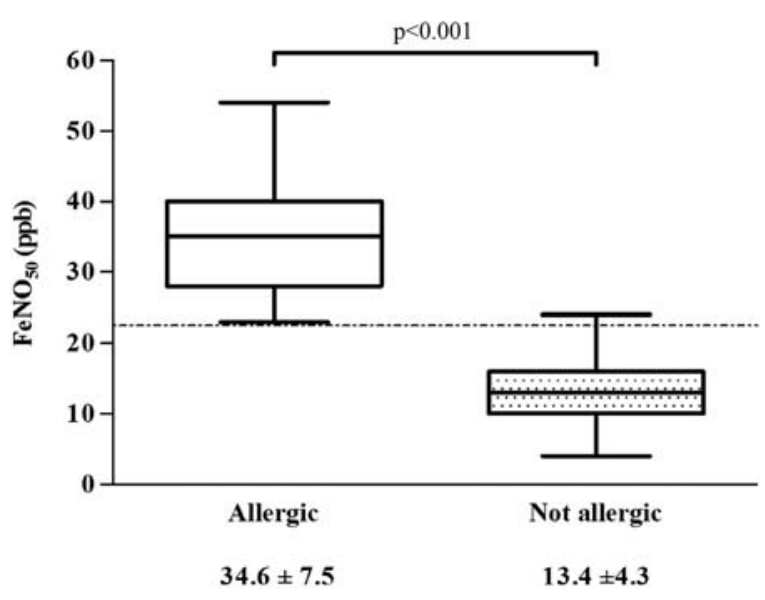

Figure 1 Fraction of exhaled nitric oxide at $50 \mathrm{~mL} / \mathrm{s}$ $\left(\mathrm{FeNO}_{50}\right)$ values in allergic and non-allergic participants. The broken line indicates our suggested cut-off value of $22.5 \mathrm{ppb}$.

individual characteristics such as race and atopy, but did not find any environmental or organisational factors that modified the frequency of sensitisation (data not shown), possibly because of the small number of participants.

Curing, as such, does not seem to be a predisposing factor because, although arthropod flora develop in curing cellars, they may also be conveyed to other environments by the hams themselves or the mechanical systems (frames and racks) used to move them.

There was no difference in the proportion of sensitised participants who were atopic or non-atopic before starting work, but there was a statistically significant difference in the latency of symptoms from the time of first exposure between the previously atopic and non-atopic participants ( $1.5 \pm 0.6$ vs $6.8 \pm 4.4$ years; student $t$ test for independent samples: $\mathrm{p}=0.037$ ), thus confirming previous observations that atopic participants develop

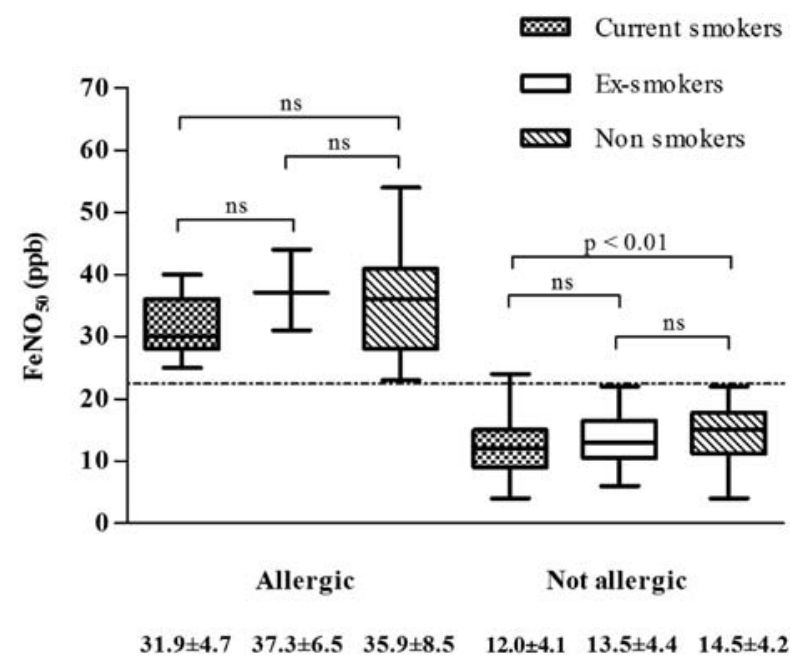

Figure 2 Fraction of exhaled nitric oxide at $50 \mathrm{~mL} / \mathrm{s}$ $\left(\mathrm{FeNO}_{50}\right)$ values in allergic and non-allergic participants by smoking habit. The broken line indicates our suggested cut-off value of $22.5 \mathrm{ppb}$. ns, not significant.
Table 5 Multiple regression model with FeNO as outcome

\begin{tabular}{lrlr} 
Predictor & \multicolumn{1}{c}{$\boldsymbol{\beta}$} & SE & Significance \\
\hline Smoking & -3.079 & 1.534 & 0.049 \\
Exposure & 2.378 & 1.629 & 0.149 \\
SPT & 17.873 & 1.662 & $<0.001$ \\
Age (years) & 0.022 & 0.082 & 0.788 \\
VAS & 1.232 & 0.589 & 0.041 \\
\hline
\end{tabular}

$\beta=$ slope of single predictors.

FeNO, fraction of exhaled nitric oxide; SE, standard error; SPT, skin prick testing; VAS, visual analogue scale.

symptoms within 3 years' exposure to airborne sensitising agents. ${ }^{44-47}$ These findings indicate that occupational health practitioners are justified in adopting a prudential attitude towards atopic participants exposed to a sensitising risk factor, even though this is not the only consideration, because many workers develop symptoms after the beginning of exposure that need to be promptly interpreted.

With regard to co-sensitisation $\mathrm{HDM} / \mathrm{SM}$, our data demonstrated that $94 \%$ of exposed workers have co-sensitisation, but we hypothesised that this is not only attributable to cross-reaction, because $88 \%$ of controls are sensitised to HDM but not to SM. The development of sensitisation to SM could be secondary to occupational exposure rather than to cross-reaction. However, studies on molecular component resolvent diagnosis could help to better elucidate the patient sensitisation profile.

We also assessed the presence of early changes in lung function and markers of airway inflammation in an attempt to improve the medical surveillance of exposed workers at risk of sensitisation. Spirometry is widely used to monitor participants exposed to work-related irritants or sensitisers, but there was no difference in the spirometric parameters of our exposed and control workers (table 1). However, obstructive abnormalities can be difficult to detect during occupational screening because asthma-related obstruction may vary. The spirometric results of most participants (even those with asthma) fall within normal limits, ${ }^{48}$ so workers with borderline obstruction should undergo second-level tests, especially those working in specific environmental conditions. ${ }^{29} \mathrm{We}$ therefore looked for an early marker of alterations suggesting airway inflammation. The FeNO produced by the human lung and present in exhaled breath ${ }^{49}$ is recognised as a safe and useful means of diagnosing airway inflammation. ${ }^{50}$ Position papers from the ERS and ATS have shown that FeNO levels are high in many diseases, including asthma and atopy, ${ }^{50}{ }^{51}$ and many epidemiological studies have used FeNO to assess early changes in airway inflammation in different real life exposure to ambient and occupational pollutants. ${ }^{52} 53$ High FeNO levels have been shown in sensitised workers after specific challenges with inhaled isocyanates ${ }^{54}{ }^{55}$ and latex, ${ }^{56}$ in sensitised participants exposed to laboratory animals ${ }^{57}$ and latex,$^{58}$ and in bakers, farmers, healthcare workers ${ }^{59}$ and workers exposed to nanomaterials. ${ }^{60}$ Elevated FeNO 
levels have also been shown to be associated with increased airway responsiveness in lifeguards working in indoor swimming pools. ${ }^{61}$ However, a number of casecontrol studies have found no differences in FeNO levels between workers exposed to airway irritants and controls; ${ }^{62-65}$ this could also be due to the known FeNO confounding factors, such as cigarette smoking, atopy, airway infections and medications, which might interfere with FeNO interpretation. ${ }^{66} 67$

None of our participants were taking inhaled corticosteroid therapy or had a respiratory tract infection during the execution of the test but, although our data confirm the effect of tobacco smoking in non-allergic participants, ${ }^{68}$ there was no clear statistically significant difference between the current smokers and non-smokers among the allergic participants, possibly because of the prevalently inflammatory effect on the airways.

We also found that, regardless of exposure, FeNO levels were higher in sensitised than in healthy workers (34.65 \pm 7.49 vs $13.29 \pm 4.29 \mathrm{ppb} ; \mathrm{p}<0.001)$ thus suggesting the presence of bronchial and nasal involvement, even if lung function parameters are normal. A cut-off value of 22.5 $\mathrm{ppb}$ proved to be highly sensitive and specific in distinguishing non-sensitised participants, and is similar to the value suggested by the ATS as a warning for inflammatory airway disorders regardless of smoking status. ${ }^{34} 51$

It has long been debated whether FeNO can identify atopy or airway inflammation. ${ }^{69}$ We found that $\mathrm{FeNO}_{50}$ levels in symptomatic participants were positively influenced by the presence of IgE-mediated allergy and the VAS-assessed severity of reported symptoms, and negatively by smoking, and the finding of a correlation between $\mathrm{FeNO}_{50}$ values and VAS scores, in SPT-positive and SPT-negative symptomatic participants, suggests that higher FeNO values may indicate IgE-mediated airway inflammation, as well as possibly a generic inflammatory response.

One limitation of our study is that we did not make an environmental assessment or determine the SM species qualitatively or quantitatively, and further assessments will be required to deal with this issue. However, in a recent European Academy of Allergy and Clinical Immunology (EAACI) position paper ${ }^{70}$ biomonitoring of aeroallergens is mainly useful for establishing doseresponse relationships in population studies.

In conclusion, our data demonstrate that FeNO, in combination with spirometry, can be proposed as a useful means of identifying workers at risk of airway inflammation who should be encouraged to undergo SPT or methacholine test.

Ham processing workers, as well as workers involved in any meat processing work that includes curing, should be informed about the occupational risk of sensitisation to mites, and monitored for the development of asthma in order to implement health assessment and preventive measures.

Contributors FT, ER and MC substantially contributed to the conception and design of the study. FT and MM obtained the data. FT, MG, AM and MC analysed and interpreted the data. FT and MC drafted the manuscript, and all the authors revised it critically for important intellectual content, and approved the final version of the submitted manuscript.

Funding This research received no specific grant from any funding agency in the public, commercial or not-for-profit sectors.

Competing interests None declared.

Patient consent Obtained.

Ethics approval The study was approved by the local Ethics Committee (the Comitato Etico Unico Provinciale di Parma) under protocol approval Number 24965.

Provenance and peer review Not commissioned; externally peer reviewed.

Data sharing statement No additional data are available.

Open Access This is an Open Access article distributed in accordance with the Creative Commons Attribution Non Commercial (CC BY-NC 4.0) license, which permits others to distribute, remix, adapt, build upon this work noncommercially, and license their derivative works on different terms, provided the original work is properly cited and the use is non-commercial. See: http:// creativecommons.org/licenses/by-nc/4.0/

\section{REFERENCES}

1. Simplicio EC, Silva DA, Braga IA, et al. Mite and pet allergen exposure in hotels in Uberlandia, Midwestern Brazil. Indoor Air 2007; 17:278-83.

2. Cates EC, Fattouh R, Johnson JR, et al. Modeling responses to respiratory house dust mite exposure. Contrib Microbiol 2007;14:42-67.

3. Murray CS, Woodcock A, Custovic A. The role of indoor allergen exposure in the development of sensitization and asthma. Curr Opin Allergy Clin Immunol 2001;1:407-12.

4. Diette GB, McCormack MC, Hansel NN, et al. Environmental issues in managing asthma. Respir Care 2008;53:602-15. discussion 616-17.

5. Bush RK. Indoor allergens, environmental avoidance, and allergic respiratory disease. Allergy Asthma Proc 2008;29:575-9.

6. Arlian LG, Morgan MS. Biology, ecology, and prevalence of dust mites. Immunol Allergy Clin North Am 2003;23:443-68.

7. Fernandez-Caldas E, Iraola V, Carnes J. Molecular and biochemical properties of storage mites (except Blomia species). Protein Pept Lett 2007;14:954-9.

8. Cuthbert OD, Brostoff J, Wraith DG, et al. 'Barn allergy': asthma and rhinitis due to storage mites. Clin Allergy 1979;9:229-36.

9. Terho EO, Husman K, Vohlonen I, et al. Allergy to storage mites or cow dander as a cause of rhinitis among Finnish dairy farmers. Allergy 1985;40:23-6.

10. van Hage-Hamsten M, Johansson SG, Höglund S, et al. Storage mite allergy is common in a farming population. Clin Allergy 1985;15:555-64.

11. Revsbech $P$, Andersen $G$. Storage mite allergy among grain elevator workers. Allergy 1987;42:423-9.

12. Blainey $A D$, Topping MD, Ollier $S$, et al. Allergic respiratory disease in grain workers: the role of storage mites. J Allergy Clin Immunol 1989;84:296-303.

13. Revsbech $\mathrm{P}$, Dueholm $\mathrm{M}$. Storage mite allergy among bakers. Allergy 1990;45:204-8.

14. Armentia A. Occupational asthma from storage mites contaminating foods. J Investig Allergol Clin Immunol 1997;7:407-8.

15. Ruoppi P, Koistinen T, Pennanen S. Sensitisation to mites in laboratory animal workers with rhinitis. Occup Environ Med 2005;62:612-15.

16. Roponen M, Kiviranta J, Seuri M, et al. Inflammatory mediators in nasal lavage, induced sputum and serum of employees with rheumatic and respiratory disorders. Eur Respir J 2001;18:542-8.

17. Luczynska CM, Griffin P, Davies RJ, et al. Prevalence of specific IgE to storage mites (A. siro, L. destructor and T. longior) in an urban population and crossreactivity with the house dust mite (D. pteronyssinus). Clin Exp Allergy 1990;20:403-6.

18. Ebner $\mathrm{C}$, Feldner $\mathrm{H}$, Ebner $\mathrm{H}$, et al. Sensitization to storage mites in house dust mite (Dermatophagoides pteronyssinus) allergic patients. Comparison of a rural and an urban population. Clin Exp Allergy 1994;24:347-52.

19. Iversen M, Dahl R. Allergy to storage mites in asthmatic patients and its relation to damp housing conditions. Allergy 1990;45:81-5.

20. Tee RD. Allergy to storage mites. Clin Exp Allergy 1994;24:636-40. 
21. Müsken $\mathrm{H}$, Fernández-Caldas $\mathrm{E}$, Marañón $\mathrm{F}$, et al. In vivo and in vitro sensitization to domestic mites in German urban and rural allergic patients. J Investig Allergol Clin Immunol 2002:12:177-81.

22. Droste J, Myny K, Van Sprundel M, et al. Allergic sensitization, symptoms, and lung function among bakery workers as compared with a nonexposed work population. J Occup Environ Med 2003;45:648-55

23. van der Heide $\mathrm{S}$, Niemeijer NR, Hovenga $\mathrm{H}$, et al. Prevalence of sensitization to the storage mites Acarus siro, Tyrophagus putrescentiae, and Lepidoglyphus destructor in allergic patients with different degrees of sensitization to the house-dust mite Dermatophagoides pteronyssinus. Allergy 1998;53:426-30.

24. van Hage-Hamsten M, Johansson SG. Storage mites. Exp Appl Acarol 1992;16:117-28.

25. Griffin P, Ford AW, Alterman L, et al. Allergenic and antigenic relationship between three species of storage mite and the house dust mite, Dermatophagoides pteronyssinus. J Allergy Clin Immuno 1989;84:108-17.

26. Morales M, Iraola V, Leonor JR, et al. Different sensitization to storage mites depending on the co-exposure to house dust mites. Ann Allergy Asthma Immunol 2015;114:36-42.

27. Roberts G, Mylonopoulou M, Hurley C, et al. Impairment in quality of life is directly related to the level of allergen exposure and allergic airway inflammation. Clin Exp Allergy 2005;35:1295-300.

28. Laszlo G. Standardisation of lung function testing: helpful guidance from the ATS/ERS Task Force. Thorax 2006;61:744-6.

29. Pellegrino R, Viegi G, Brusasco V, et al. Interpretative strategies for lung function tests. Eur Respir J 2005;26:948-68.

30. Quanjer PH, Stanojevic S, Cole TJ, et al. Multi-ethnic reference values for spirometry for the 3-95-yr age range: the global lung function 2012 equations. Eur Respir J 2012;40:1324-43.

31. Sterk PJ, Fabbri LM, Quanjer PH, et al. Airway responsiveness. Standardized challenge testing with pharmacological, physical and sensitizing stimuli in adults. Report Working Party Standardization of Lung Function Tests, European Community for Steel and Coal. Official Statement of the European Respiratory Society. Eur Respir J 1993;16(Suppl):53-83.

32. Crapo RO, Casaburi R, Coates AL, et al. Guidelines for methacholine and exercise challenge testing-1999. This official statement of the American Thoracic Society was adopted by the ATS Board of Directors, July 1999. Am J Respir Crit Care Med 2000;161:309-29.

33. Quirce S. IgE antibodies in occupational asthma: are they causative or an associated phenomenon? Curr Opin Allergy Clin Immunol 2014; $14: 100-5$

34. American Thoracic Society, European Respiratory Society. ATS/ERS recommendations for standardized procedures for the online and offline measurement of exhaled lower respiratory nitric oxide and nasal nitric oxide, 2005. Am J Respir Crit Care Med 2005;171:912-30.

35. Antunes J, Borrego L, Romeira A, et al. Skin prick tests and allergy diagnosis. Allergol Immunopathol (Madr) 2009;37:155-64.

36. Yadav A, Elder BL, Morgan MS, et al. Prevalence of serum IgE to storage mites in a southwestern Ohio population. Ann Allergy Asthma Immunol 2006;96:356-62.

37. Moscato G, Vandenplas O, Van Wijk RG, et al., European Academy of Allergology and Clinical Immunology. EAACI position paper on occupational rhinitis. Respir Res 2009;10:16.

38. Henneberger PK, Redlich CA, Callahan DB, et al. An official American Thoracic Society statement: work-exacerbated asthma. Am J Respir Crit Care Med 2011;184:368-78.

39. Bauchau V, Durham SR. Prevalence and rate of diagnosis of allergic rhinitis in Europe. Eur Respir J 2004;24:758-64.

40. Greiner AN, Hellings PW, Rotiroti G, et al. Allergic rhinitis. Lancet 2011;378:2112-22.

41. Moscato G, Siracusa A. Rhinitis guidelines and implications for occupational rhinitis. Curr Opin Allergy Clin Immunol 2009;9:110-15.

42. Bousquet J, Khaltaev N, Cruz AA, et al. Allergic rhinitis and its impact on asthma (ARIA) 2008 update (in collaboration with the World Health Organization, GA(2)LEN and AllerGen). Allergy 2008;63(Suppl 86):8-160.

43. Hennekens $\mathrm{CH}$, Buring JE. Epidemiology in medicine. 1st edn. Boston. Little, Brown, 1987.

44. Gautrin D, Infante-Rivard C, Ghezzo $\mathrm{H}$, et al. Incidence and host determinants of probable occupational asthma in apprentices exposed to laboratory animals. Am J Respir Crit Care Med 2001;163:899-904.
45. Ruoppi P, Koistinen T, Susitaival P, et al. Frequency of allergic rhinitis to laboratory animals in university employees as confirmed by chamber challenges. Allergy 2004;59:295-301.

46. Cullinan P, Cook A, Gordon S, et al. Allergen exposure, atopy and smoking as determinants of allergy to rats in a cohort of laboratory employees. Eur Respir J 1999;13:1139-43.

47. Corradi M, Romano C, Mutti A. Laboratory animal; allergy; asthma. Med Lav 2011;102:428-44. Italian

48. Szram J, Cullinan P. Medical surveillance for prevention of occupational asthma. Curr Opin Allergy Clin Immunol 2013;13:138-44.

49. Kharitonov SA, Barnes PJ. Exhaled markers of pulmonary disease. Am J Respir Crit Care Med 2001;163:1693-722.

50. American Thoracic Society Workshop. ATS Workshop Proceedings: exhaled nitric oxide and nitric oxide oxidative metabolism in exhaled breath condensate: executive summary. Am J Respir Crit Care Med 2006;173:811-13

51. Dweik RA, Boggs PB, Erzurum SC, et al., American Thoracic Society Committee on Interpretation of Exhaled Nitric Oxide Levels (FENO) for Clinical Applications. An official ATS clinical practice guideline: interpretation of exhaled nitric oxide levels (FENO) for clinical applications. Am J Respir Crit Care Med 2011;184:602-15.

52. Eckel SP, Berhane K, Salam MT, et al. Residential traffic-related pollution exposures and exhaled nitric oxide in the children's health study. Environ Health Perspect 2011;119:1472-7.

53. Berhane K, Zhang Y, Linn WS, et al. The effect of ambient air pollution on exhaled nitric oxide in the Children's Health Study. Eur Respir J 2011;37:1029-36.

54. Barbinova L, Baur X. Increase in exhaled nitric oxide (eNO) after work-related isocyanate exposure. Int Arch Occup Environ Health 2006;79:387-95.

55. Ferrazzoni S, Scarpa MC, Guarnieri G, et al. Exhaled nitric oxide and breath condensate $\mathrm{pH}$ in asthmatic reactions induced by isocyanates. Chest 2009;136:155-62.

56. Baur X, Barbinova L. Latex allergen exposure increases exhaled nitric oxide in symptomatic healthcare workers. Eur Respir $J$ 2005;25:309-16.

57. Hewitt RS, Smith AD, Cowan JO, et al. Serial exhaled nitric oxide measurements in the assessment of laboratory animal allergy. $J$ Asthma 2008;45:101-7.

58. de Broucker V, Hulo S, Cherot-Kornobis N, et al. Interest of exhaled biomarkers in occupational asthma to latex: a case report. Arch Environ Occup Health 2012;67:170-6.

59. Swierczyńska-Machura D, Krakowiak A, Wiszniewska M, et al. Exhaled nitric oxide levels after specific inahalatory challenge test in participants with diagnosed occupational asthma. Int J Occup Med Environ Health 2008;21:219-25.

60. Wu WT, Liao HY, Chung YT, et al. Effect of nanoparticles exposure on fractional exhaled nitric oxide (FENO) in workers exposed to nanomaterials. Int J Mol Sci 2014;15:878-94.

61. Demange $\mathrm{V}$, Bohadana A, Massin N, et al. Exhaled nitric oxide and airway hyperresponsiveness in workers: a preliminary study in lifeguards. BMC Pulm Med 2009;9:53.

62. Chérot-Kornobis $\mathrm{N}$, Hulo $\mathrm{S}$, de Broucker $\mathrm{V}$, et al. Induced sputum, exhaled NO, and breath condensate in occupational medicine. J Occup Environ Med 2012;54:922-7.

63. Sakwari G, Mamuya SH, Bråtveit M, et al. Respiratory symptoms, exhaled nitric oxide, and lung function among workers in Tanzanian coffee factories. J Occup Environ Med 2013;55:544-51.

64. Tungu AM, Bråtveit M, Mamuya SD, et al. Fractional exhaled nitric oxide among cement factory workers: a cross sectional study. Occup Environ Med 2013;70:289-95.

65. Sauni R, Oksa P, Lehtimäki L, et al. Increased alveolar nitric oxide and systemic inflammation markers in silica-exposed workers. Occup Environ Med 2012:69:256-60.

66. Olivieri M, Talamini G, Corradi M, et al. Reference values for exhaled nitric oxide (REVENO) study. Respir Res 2006;7:94

67. Barnes PJ, Dweik RA, Gelb AF, et al. Exhaled nitric oxide in pulmonary diseases: a comprehensive review. Chest 2010;138:682-92.

68. Nadif R, Matran R, Maccario J, et al. Passive and active smoking and exhaled nitric oxide levels according to asthma and atopy in adults. Ann Allergy Asthma Immunol 2010;104:385-93.

69. Olin AC, Alving K, Torén K. Exhaled nitric oxide: relation to sensitization and respiratory symptoms. Clin Exp Allergy 2004;34:221-6.

70. Raulf M, Buters J, Chapman M, et al. Monitoring of occupational and environmental aeroallergens-EAACI Position Paper: concerted action of the EAACI IG Occupational Allergy and Aerobiology \& Air Pollution. Allergy 2014t;69:1280-99. 